\title{
Caspase-12 and endoplasmic reticulum stress mediate neurotoxicity of pathological prion protein
}

\author{
Claudio Hetz ${ }^{1,2}$, \\ Milene Russelakis-Carneiro ${ }^{1}$, \\ Kinsey Maundrell ${ }^{1}$, Joaquin Castilla ${ }^{1,3}$ and \\ Claudio Soto $1,3,4$ \\ ${ }^{1}$ Serono Pharmaceutical Research Institute, 14 Chemin des Aulx, \\ 1228 Plan les Ouates, Switzerland, ${ }^{2}$ Instituto de Ciencias Biomédicas, \\ Universidad de Chile, Santiago, Chile and ${ }^{3}$ Department of Neurology, \\ University of Texas Medical Branch, Galveston, Texas, TX, USA \\ ${ }^{4}$ Corresponding author \\ e-mail: clsoto@utmb.edu
}

Prion diseases are characterized by accumulation of misfolded prion protein $\left(\mathrm{PrP}^{\mathrm{Sc}}\right)$, and neuronal death by apoptosis. Here we show that nanomolar concentrations of purified $\mathrm{PrP}^{\mathrm{Sc}}$ from mouse scrapie brain induce apoptosis of $\mathbf{N 2 A}$ neuroblastoma cells. PrPSc toxicity was associated with an increase of intracellular calcium released from endoplasmic reticulum (ER) and up-regulation of several ER chaperones. Caspase-12 activation was detected in cells treated with PrPsc, and cellular death was inhibited by overexpression of a catalytic mutant of caspase-12 or an ER-targeted Bcl-2 chimeric protein. Scrapie-infected N2A cells were more susceptible to ER-stress and to PrPSc toxicity than non-infected cells. In scrapie-infected mice a correlation between caspase-12 activation and neuronal loss was observed in histological and biochemical analyses of different brain areas. The extent of prion replication was closely correlated with the up-regulation of ER-stress chaperone proteins. Similar results were observed in humans affected with sporadic and variant Creutzfeldt-Jakob disease, implicating for the first time the caspase-12 dependent pathway in a neurodegenerative disease in vivo, and thus offering novel potential targets for the treatment of prion disorders.

Keywords: apoptosis/caspase-12/Creutzfeldt-Jakob disease/ER-stress/PrPSc/scrapie

\section{Introduction}

Transmissible spongiform encephalopathies (TSEs), also known as prion disorders, are a group of clinically diverse, but mechanistically similar neurological diseases, such as Creutzfeldt-Jakob disease (CJD) in humans and bovine spongiform encephalopathy (BSE), scrapie and chronic wasting disease in animals. The hallmark pathological features of TSEs are the spongiform degeneration of the brain, accompanied by extensive neuronal loss, astrogliosis, and cerebral accumulation of a misfolded and protease-resistant form of the prion protein (Prusiner, 1998). No amino acid sequence or posttranslational differences have been detected between the normal host cell surface protein, $\operatorname{PrP}^{\mathrm{C}}$, and its pathological form, $\mathrm{PrP}^{\mathrm{Sc}}$. The conversion of $\mathrm{PrP}^{\mathrm{C}}$ into $\mathrm{PrP}^{\mathrm{Sc}}$ involves a conformational change whereby the $\alpha$ helical content diminishes and the amount of $\beta$-sheet increases (Prusiner, 1998).

Apoptosis is a programmed form of cell death, which plays a central role during development and homeostasis of multicellular organisms and has been implicated in a number of pathological conditions (Vaux and Korsmeyer, 1999; Reed, 2002). The central executioner molecules of apoptosis are a large family of cysteine proteases known as caspases (Budihardjo et al., 1999; Takahashi, 1999). Activation of caspase-dependent apoptosis may be initiated by cell surface receptors or by mitochondrial stress (Budihardjo et al., 1999). Recently, another apoptoticregulatory pathway has been described, in which the induction of endoplasmic reticulum (ER) stress due to alteration of calcium homeostasis or accumulation of misfolded proteins, triggers the activation of an ERresident caspase, termed caspase-12 (Nakagawa et al., 2000).

Apoptosis has been described in the brains of patients affected by CJD, Fatal Familial Insomnia, scrapie-infected hamsters, mice and sheep (review in Hetz and Soto, 2003). Although a considerable effort has been made to understand the molecular basis of prion conversion, little is known about the mechanism by which this process is associated with the disease. Attempts to understand the molecular basis of neuronal dysfunction in prion diseases have led to the search for in vitro models to analyze the role of $\mathrm{PrP}^{\mathrm{Sc}}$ in cellular death. The prion protein fragment spanning the sequence 106126 (PrP106-126), corresponding to a putative transmembrane region of $\mathrm{PrP}^{\mathrm{C}}$, has been extensively used to induce cell death in neuronal cultures (Forloni et al., 1993; O'Donovan et al., 2001). The major drawback of using PrP106-126 as a model is that although this sequence is present in several longer peptides isolated from cerebral amyloid plaques of patients suffering from GSS (Ghetti et al., 1996), the PrP106-126 peptide as such has never been found in vivo. Therefore, the relevance of the findings obtained with this peptide remains to be determined. The major aim of this study was to characterize the signaling pathways involved in neuronal death induced by highly purified $\mathrm{PrP}^{\mathrm{Sc}}$ from mouse brains infected with experimental scrapie. It has been reported earlier that purified $\mathrm{PrPSc}^{\mathrm{Sc}}$ leads to cell death (Post et al., 2000). However, the mechanism of cell death was not studied. Our findings show that $\mathrm{PrP}^{\mathrm{Sc}}$-induced apoptosis in vitro is associated with the induction of ER-stress and activation of caspase-12. Histological and biochemical analysis of brains from scrapie-sick mice and from humans affected by sporadic 
A
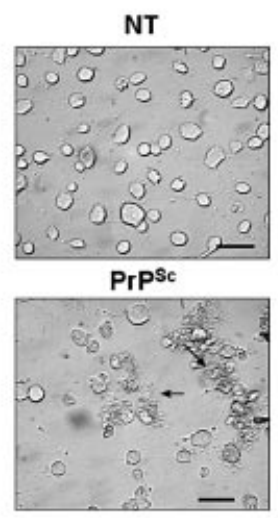

C

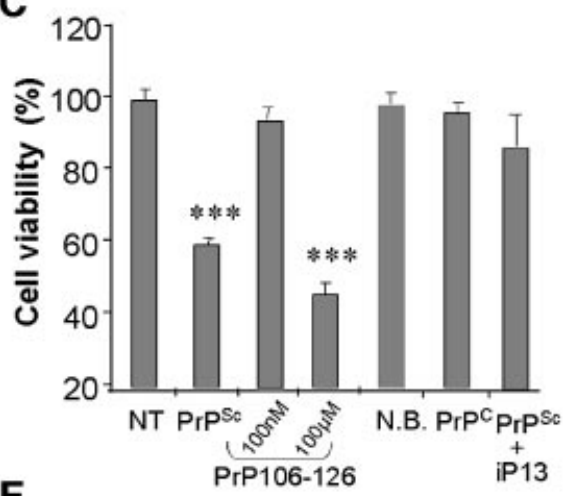

E

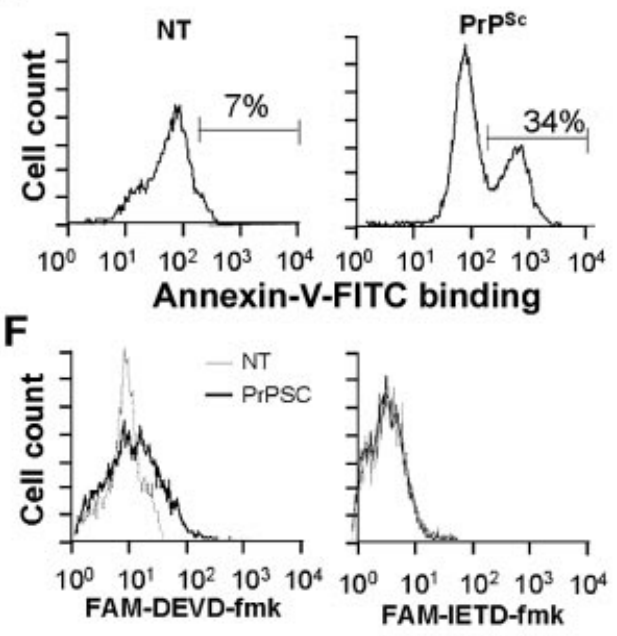

B

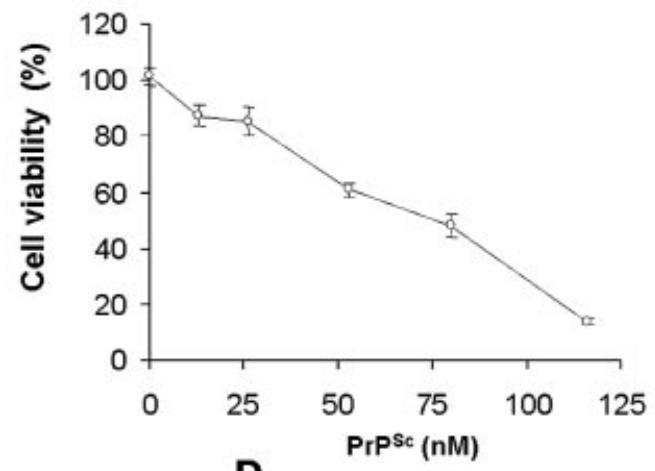

D

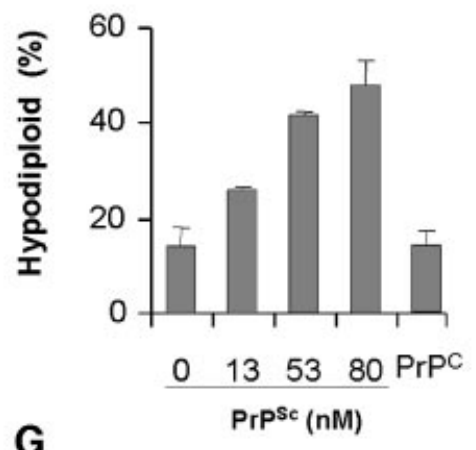

G

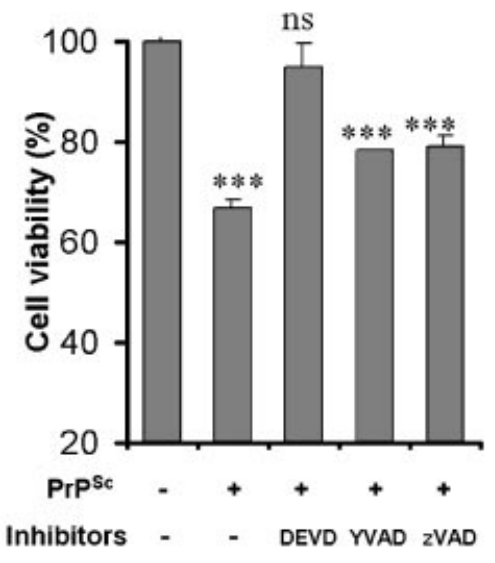

Fig. 1. Purified PrPSc from 139A-scrapie infected brains induces caspase-3 dependent apoptosis of N2A cells. (A) Morphological changes observed in N2A neuroblastoma cells treated with $50 \mathrm{nM} \mathrm{PrPSc}$ for $48 \mathrm{~h}$. (B) N2A cells were treated with different concentrations of PrPsc and cell viability was analyzed after $48 \mathrm{~h}$ by MTS assay. (C) As controls, cells were incubated with: $165 \mathrm{nM}$ of recombinant mouse $\operatorname{PrP} \mathrm{P}^{\mathrm{C}} ; 50 \mathrm{nM} \mathrm{PrPSc}$ pre-treated with $300 \mathrm{nM}$ of $\beta$-sheet breaker peptide iPrP13 to decrease PrPSc- $\beta$ sheet content; $100 \mathrm{nM}$ or $100 \mu \mathrm{M}$ of aggregated PrP106-126 peptide for 7 days; or $0.5 \%(\mathrm{v} / \mathrm{v})$ preparation of normal brain homogenate following the same procedure as to purify $\operatorname{PrP}^{\mathrm{Sc}}(\mathrm{N} . \mathrm{B}$.). (D) Cells were incubated for $48 \mathrm{~h}$ with different concentrations of $\mathrm{PrP}^{\mathrm{Sc}}, 100 \mathrm{nM}$ recombinant $\mathrm{PrP}^{\mathrm{C}}$ or left untreated. Subsequently, cells were stained with PI and hypodiploid cell population was quantified by FACS analysis. (E) Cells were treated with $66 \mathrm{nM} \mathrm{PrPSc}$ for $6 \mathrm{~h}$ and then phosphatidylserine exposure on the cell surface was detected using annexin V-FITC. (F) Caspase-3 and caspase-8 activity in situ was determined by flow cytometry using the cell permeable substrates FAM-DEVD-fmk and FAM-IETD-fmk after treatment with PrPSc for $20 \mathrm{~h}$. Non-treated cells (gray line), or cells treated with $50 \mathrm{nM}$ PrPSc (black line). (G) Cells were incubated for $60 \mathrm{~min}$ with or without $100 \mu \mathrm{M}$ Ac-DEVD-fmk (DEVD), $100 \mu \mathrm{M}$ Ac-YVAD-fmk (YVAD) or $10 \mu \mathrm{M}$ zVAD-fmk (zVAD). Then, PrPSc was added to a final concentration of $50 \mathrm{nM}$, and after $48 \mathrm{~h}$ cell survival was determined by the MTS assay. Data shown in (C, $\mathrm{D}$ and $\mathrm{G}$ ) correspond to the means and standard deviations at two independent experiments performed in triplicate. Statistical analysis was performed by parametric $t$-test comparing each value with the untreated control.

CJD (sCJD) and variant CJD (vCJD) showed the presence of activated caspase-12 and ER-stress inducible chaperones in brain areas exhibiting extensive neuronal death.
These findings provide a novel target for TSE therapy and suggest a general mechanism of cell death in chronic neurodegenerative diseases. 


\section{Results}

Purified mouse PrPSc induces caspase-3-dependent apoptosis in N2A cells

$\mathrm{N} 2 \mathrm{~A}$ cells were chosen to characterize neurotoxicity of $\mathrm{PrP}^{\mathrm{Sc}}$ purified from 139A scrapie-infected brains. N2A neuroblastoma cells were grown for $24 \mathrm{~h}$ in normal culture medium with low serum, and then different concentrations of $\mathrm{PrP}^{\mathrm{Sc}}$ were added to the medium. After $48 \mathrm{~h}$ of incubation, the cells treated with $\operatorname{PrP}^{\mathrm{Sc}}$ showed abnormal morphological changes, including cell shrinkage and aggregation of the cell bodies, followed by detachment of cells from the culture plate (Figure 1A). Quantification of cellular viability after $\mathrm{PrPSc}^{\mathrm{Sc}}$ treatment revealed that cellular death occurred in a concentration-dependent manner in the nanomolar range (Figure 1B). Several controls were performed. First, to rule out the possibility that toxicity might be caused by contaminants carried over from the purification procedure, cells were treated with equivalent volumes of a sample prepared under the same conditions, but starting with normal mouse brains. The results showed no effect of this preparation (Figure 1C). In addition, experiments in which cells were treated with recombinant mouse $\operatorname{PrP}^{\mathrm{C}}(165 \mathrm{nM})$ showed no effect on neuronal survival (Figure 1C), suggesting that $\mathrm{PrPSc}^{\mathrm{Sc}}$ toxicity is associated with its pathological conformation. In agreement with this hypothesis, pre-incubation of $\mathrm{PrPSc}^{\mathrm{Sc}}$ with a small peptide that disrupts the $\beta$-sheet structure (peptide iPrP13), leads to a significant decrease in the toxicity of the protein (Figure 1C). We have previously shown that iPrP13 decreases the $\beta$-sheet structure of $\mathrm{PrP}^{\mathrm{Sc}}$, converting it into a protease-sensitive $\operatorname{PrP}^{\mathrm{C}}$-like molecule (Soto et al., 2000). Finally, treatment of the cells with $100 \mathrm{nM}$ PrP106-126 did not produce any cell death (Figure 1C). Cytotoxicity with this peptide was observed only when cells were treated with 1000-fold higher concentration $(100 \mu \mathrm{M})$, compared with pure $\mathrm{PrP}^{\mathrm{Sc}}$, and only after several days of incubation in culture (Figure 1C). These data suggest that $\mathrm{PrPSc}^{\mathrm{Sc}}$ neurotoxicity cannot simply be explained by a non-specific effect of an aggregated hydrophobic protein preparation.

Quantification of DNA content after PI-staining revealed that hypodiploid cells could be detected after PrPSc treatment in a dose-dependent manner (Figure 1D). As controls, we used cells treated with recombinant $\operatorname{PrPC}^{\mathrm{C}}$, which showed no indication of apoptotic induction (Figure 1D). PrPSc-induced apoptosis was additionally confirmed by phosphatidylserine externalization to the cell surface, which is commonly observed at early stages of apoptosis. Appearance of phosphatidylserine at the cell surface was observed in 34\% of the cells $6 \mathrm{~h}$ after treatment with $66 \mathrm{nM} \mathrm{PrPSc}$ (Figure 1E). Overall, these data indicate that nanomolar concentrations of purified $\mathrm{PrP}^{\mathrm{Sc}}$ induce cellular death by apoptosis.

To characterize the signalling pathways involved in

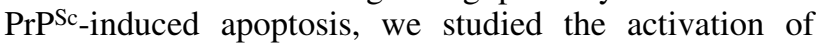
different caspases using cell permeable fluorogenic substrates (FAM-YEVD-fmk, FAM-DEVD-fmk, and FAMIETD-fmk) to detect caspase-1, caspase-3 and caspase-8 activity, respectively. After $\mathrm{PrPSc}^{\mathrm{Sc}}$ treatment, caspase-3 activation was observed progressively over time, reaching a maximum level at $\sim 20 \mathrm{~h}$ (Figure $1 \mathrm{~F}$ ). However, no significant activation of caspase-8 or caspase-1 was
A

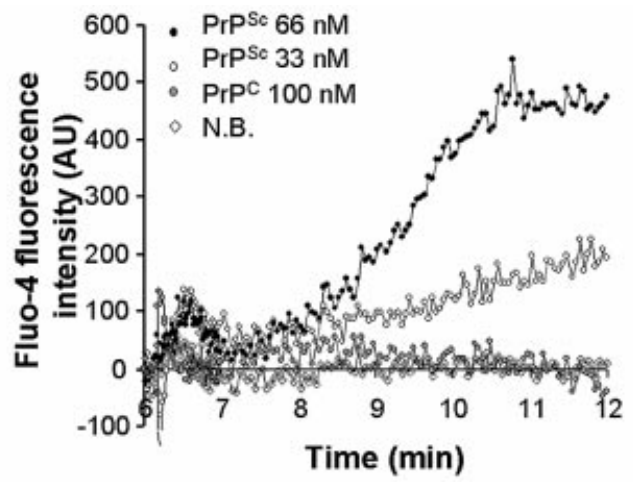

B
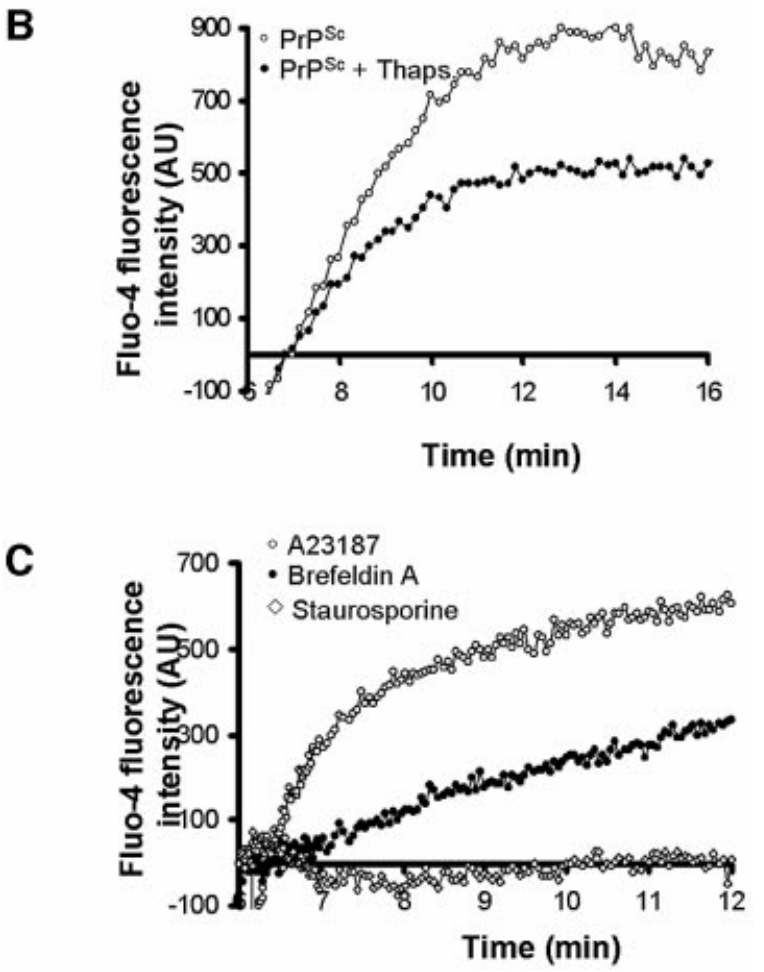

Fig. 2. $\mathrm{Pr} \mathrm{P}^{\mathrm{Sc}}$ induces a release of $\mathrm{Ca}^{2+}$ from the endoplasmic reticulum. (A) N2A cells were loaded with the $\mathrm{Ca}^{2+}$ dye Fluo-4 $(10 \mu \mathrm{g} / \mathrm{ml}$ final concentration). Changes in fluorescence intensity were measured by using the FLIPR1 setup after addition of 33 or $66 \mathrm{nM} P r P^{S c}$, $100 \mathrm{nM}$ recombinant $\operatorname{PrPC}^{\mathrm{C}}$, or $0.5 \%(\mathrm{v} / \mathrm{v})$ of a preparation from normal mouse brains (N.B.). Relative fluorescence intensity was plotted against time, and represents the average of three different experiments. (B) Cells were pre-treated with thapsigargin $(5 \mu \mathrm{M})$ for $15 \mathrm{~min}$ and calcium signals were analyzed over time after addition of $80 \mathrm{nM} \mathrm{PrPSc}^{\mathrm{Sc}}$. (C) Control experiments showing that ER stress induced by brefeldin $\mathrm{A}(40 \mu \mathrm{M})$ or A23187 (400 $\mathrm{nM})$, but not by staurosporine $(25 \mathrm{nM})$ promoted calcium release.

observed after $20 \mathrm{~h}$ of incubation with $\mathrm{PrPsc}^{\mathrm{Sc}}$ (Figure 1F, data not shown). Treatment of N2A cells with $100 \mu \mathrm{M}$ AcDEVD-fmk, a preferential caspase-3 inhibitor, completely abolished cellular death induced by $50 \mathrm{nM} \operatorname{PrP}^{\mathrm{Sc}}$ (Figure 1G). Treatment with $100 \mu \mathrm{M}$ Ac-YVAD-fmk, an inhibitor of interleukin-1 converting proteases, like caspase-1, or low doses of zVAD-fmk, a general caspase inhibitor that blocks mainly caspase- 8 activation at this dose (Hetz et al., 2002a), had no significant effect on

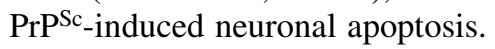




\section{PrPsc-induced apoptosis is associated with calcium release from the ER}

To investigate up-stream events involved in caspase-3 activation, we studied the effect of $\mathrm{PrP}^{\mathrm{Sc}}$ treatment on intracellular $\mathrm{Ca}^{2+}$ levels. N2A cells were loaded with the $\mathrm{Ca}^{2+}$-responsive fluorophore Fluo-4, to monitor changes in intracellular calcium concentrations over time. After treatment with $\mathrm{PrPSc}^{\mathrm{Sc}}$, a fast and sustained increase in $\mathrm{Ca}^{2+}$ levels (within minutes) was observed in a dosedependent manner (Figure 2A). As controls, cells were treated with $100 \mathrm{nM}$ recombinant $\mathrm{PrP}^{\mathrm{C}}$ or equivalent volumes of a sample prepared from non-infected brains. No effects on intracellular calcium levels were observed under these conditions (Figure 2A). These experiments were performed in the absence of extracellular calcium, indicating that $\mathrm{Ca}^{2+}$ increase stimulated by $\mathrm{PrP}^{\mathrm{Sc}}$ is released from intracellular stores, such as ER or mitochondria. In order to define the source of calcium, $\mathrm{N} 2 \mathrm{~A}$ cells were pre-treated with thapsigargin $(5 \mu \mathrm{M})$ to decrease the concentration of calcium in the ER before $\mathrm{PrP}^{\mathrm{Sc}}$ addition. Decreased calcium signals were observed in cells pre-treated with thapsigargin compared with the controls, indicating that $\mathrm{PrP}^{\mathrm{Sc}}$ induces an increase of intracellular calcium released mainly from the ER (Figure 2B). As positive controls, cells were treated with the ER-stress inducers brefeldin A (an inhibitor of ERGolgi transport) and the ionophore A23187 (Figure 2C) at concentrations that induce apoptosis in N2A cells. No changes in intracellular $\mathrm{Ca}^{2+}$ levels were observed after treatment of N2A cells with staurosporine $(500 \mathrm{nM})$, which is known to induce apoptosis by the calciumindependent mitochondrial pathway (Figure 2C).

\section{PrPSc induces ER-stress and activation of caspase-12}

The main caspase associated with the ER apoptosis pathway is caspase-12, an ER-resident caspase, which upon activation by ER-stress and calcium release can

Fig. 3. Caspase-12 activation mediates $\mathrm{PrP}^{\mathrm{Sc}}$ neurotoxicity in $\mathrm{N} 2 \mathrm{~A}$ cells. (A) Cells were treated with $\operatorname{PrP}^{\mathrm{Sc}}(50 \mathrm{nM})$, staurosporine $(25 \mathrm{nM})$ or brefeldin A $(12 \mu \mathrm{M})$, and the levels of pro-caspase-12, Grp58, Grp78, and Grp94 were determined by western blotting. As controls the levels of actin are shown. To determine the significance of the differences in expression level, data from at least three different experiments were analyzed by densitometry (see Supplementary data). Differences on the expression of pro-caspase-12 (at 24 and $27 \mathrm{~h}$ ), Grp94 (at 24 and $27 \mathrm{~h}$ ), Grp78 (at $27 \mathrm{~h}$ ) and Grp58 (at $27 \mathrm{~h}$ ) after treatment with $\mathrm{PrP}^{\mathrm{Sc}}$ were statistically significant $(P<0.005)$. (B) Expression levels of caspase-12 dominant-negative in three different clones termed DN12, DN18 and DN19 were determined by western blotting. These clones as well as a clone transfected with vector alone (C2) were treated with $80 \mathrm{nM} \mathrm{PrPSc}$ for $48 \mathrm{~h}$. Results were analyzed statistically by non-parametric $t$-test comparing each result with values obtained with the control clone $\mathrm{C} 2$. (C) As controls, the same clones were treated with A23187 $(200 \mathrm{nM})$, brefeldin A $(12 \mu \mathrm{M}$; Bref.A) or staurosporine (25 nM; Stauro), and cell viability was determined after $48 \mathrm{~h}$ by MTS analysis. In panels (B) and (C), values correspond to the average and standard deviation of three determinations. Results were statistically analyzed by $t$-test comparing the result of each treatment with the values obtained with the same treatment of clone $\mathrm{C} 2$ and results are shown in the figure, using the asterisk nomenclature as described in Materials and methods. Data were also analyzed by two-way ANOVA using clones and treatment as the variables. Results were significant with $P<0.0001$. promote caspase-3 mediated apoptosis (Mehmet, 2000). Treatment of N2A cells with PrPSc leads to activation of this protease, which is evidenced by the decrease of the pro-caspase-12 signal (Figure 3A, top panel). Similar results were observed when N2A cells were treated with lethal concentrations of brefeldin A, but not with staurosporine (Figure 3A, top panel). In addition, $\mathrm{PrP}^{\mathrm{Sc}}$ treatment was associated with a significant increase in the expression levels of the ER chaperone Grp58. A lower but still statistically significant induction of Grp94 and Grp78 was observed (Figure 3A, see Supplementary data for statistical analysis, available at The EMBO Journal

A

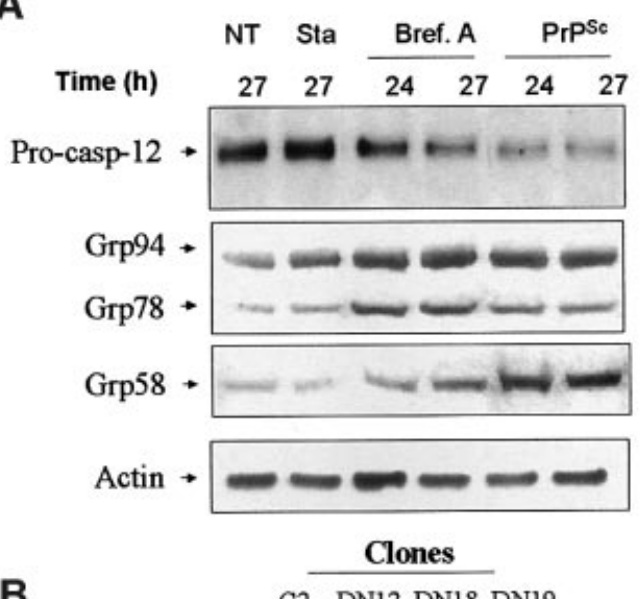

B

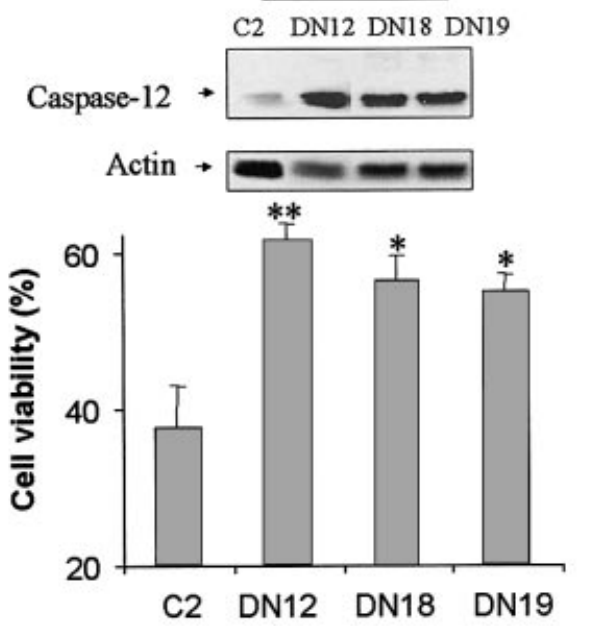

C

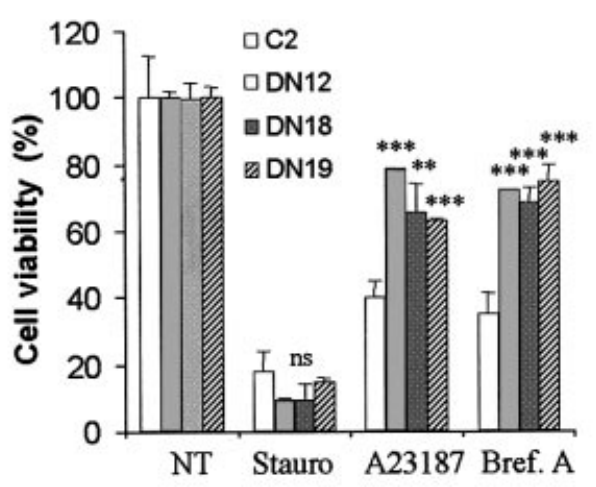


Online). No induction of Grps was observed after treatment of cells with staurosporine (Figure 3A) or with equivalent concentrations of recombinant $\operatorname{PrP}^{\mathrm{C}}$ (data not shown).

To confirm the participation of caspase-12 in the $\mathrm{PrPSc}^{\mathrm{Sc}}$ apoptotic pathway we studied the effect of over-expression of a catalytic mutant of caspase-12 [caspase-12(C298A)], that has been shown to function as a dominant-negative (Rao et al., 2002). N2A cells over-expressing the caspase12 catalytic mutant were significantly more resistant to $\mathrm{PrP}^{\mathrm{Sc}}$ toxicity (Figure 3B). As controls, the same clones were treated with different concentrations of brefeldin A, A23187 or staurosporine. Cells over-expressing the dominant-negative caspase-12 were more resistant to insult induced by the ER-stress agents brefeldin A and A23187 (Figure 3C). However, no difference was observed when an agent inducing apoptosis by the mitochondrial pathway (staurosporine) was used (Figure 3C).

Recently, it has been described that under certain pathological conditions, Bcl-2 can regulate the induction of apoptosis mediated not only by mitochondrial dysfunction, but also by ER-stress (Rudner et al., 2001; Wang et al., 2001). In order to characterize further the role of ER-mediated apoptosis in $\mathrm{PrPSc}^{\mathrm{S} \text {-induced cell }}$ death, N2A cells were stably transfected with a mutant form of Bcl-2 targeted to the ER (Bcl-2/ER) by replacing its transmembrane domain with the ER-insertional region of cytochrome b5 (Figure 4A). As controls we stably transfected cells with either a mutant form lacking the transmembrane domain $(\mathrm{Bcl}-2 / \Delta \mathrm{TM})$, which is expressed in the cytoplasm and is inactive, or with wild-type Bcl-2 (Bcl-2/WT), which is expressed in both mitochondria and ER (Figure 4A). The specific distribution of each mutant was confirmed by co-staining the cells with antibodies against Bcl-2 and the ER marker calnexin (Figure 4B). Cells transfected with Bcl-2/ER completely overlapped in double stained preparations with a perinuclear distribution typical of the ER-Golgi network. As expected, Bcl-2/DTM clones showed staining throughout the cell (including the nucleus), whereas $\mathrm{Bcl}-2 / \mathrm{WT}$ exhibited a
A

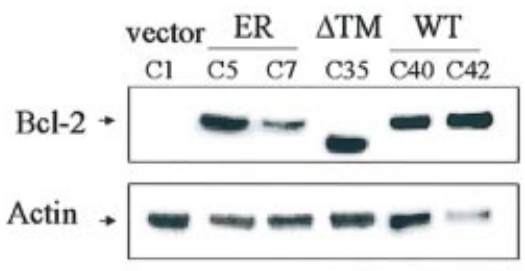

B

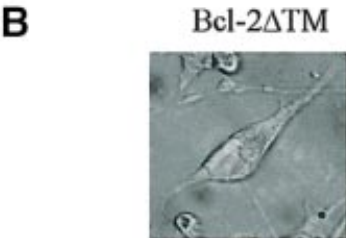

Bcl-2
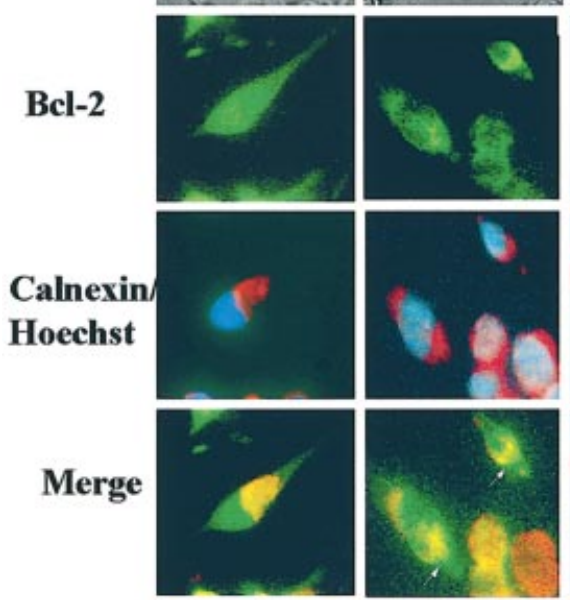

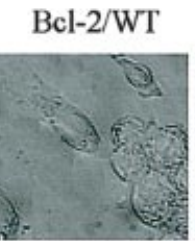

a.
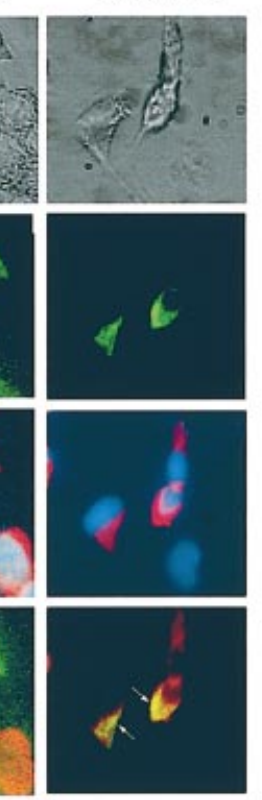

C
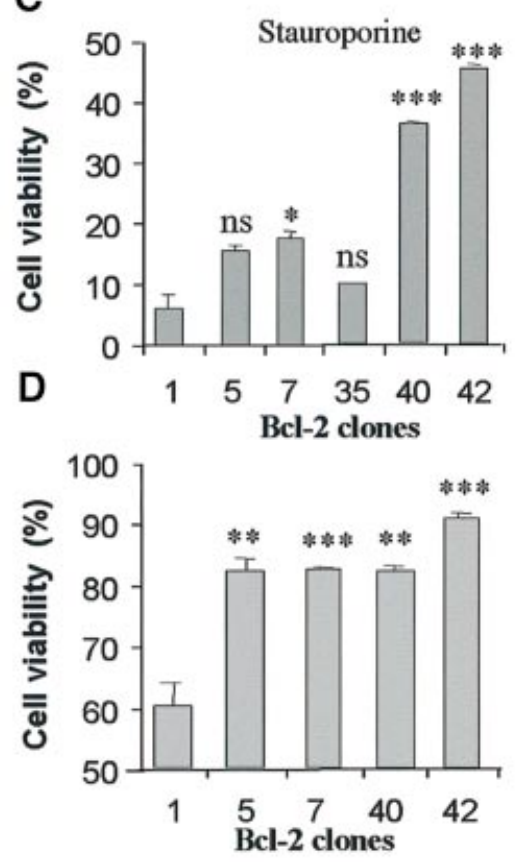

E

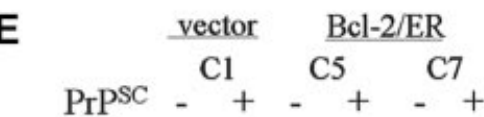

Procasp-12

Fig. 4. Bcl-2 targeted to the ER decreases the sensitivity of $\mathrm{N} 2 \mathrm{~A}$ cells to PrPs ${ }^{\mathrm{Sc}}$ toxicity and caspase-12 activation. (A) Cells were stably transfected with Bcl-2/ER, Bcl-2- $\Delta \mathrm{TM}$ and Bcl-2WT constructs or with empty vector, and Bcl-2 protein levels were analyzed by western blotting in different cellular clones. (B) In parallel, Bcl-2 distribution was detected by immunofluorescence in selected clones. Bcl-2 staining is shown in green; calnexin staining is shown in red and nuclear labeling with Hoechst33342 is shown in blue. (C) As controls, Bcl-2 transfected clones and control cells were treated with $150 \mathrm{nM}$ staurosporine for $24 \mathrm{~h}$. (D) The same N2A cell clones were treated with $50 \mathrm{nM}$ PrPSc for $48 \mathrm{~h}$, and cell viability was assessed using MTS analysis. In the last two panels, statistical analysis was performed comparing the cell viability values for each transfected clone with the results obtained with the control clone $\mathrm{C} 1$. (E) Cells transfected with vector alone (C1 clone) or with Bcl-2/ER (clones 5 and 7 ) were treated with $50 \mathrm{nM} \mathrm{PrP}^{\mathrm{Sc}}$. Caspase-12 activation was analyzed by western blot. The significance of the differences in pro-caspase-12 expression was estimated by densitometric analysis of the blots. 
cytoplasmatic distribution, which partially colocalized with calnexin (Figure 4B).

Treatment of the different cell clones with staurosporine showed that only the wild-type Bcl-2 expressing cells were significantly protected from the toxic effect of this agent (Figure 4C). The two clones expressing Bcl-2/ER (clones $\mathrm{C} 5$ and $\mathrm{C} 7$ ) showed significant protection against $\mathrm{PrP}^{\mathrm{Sc}}$ when compared with cells transfected with vector alone (Figure 4D). Moreover, cells expressing Bcl-2/WT, which is targeted to both mitochondria and ER, did not result in significantly further inhibition of neurotoxicity compared with $\mathrm{Bcl}-2 / \mathrm{ER}$, suggesting that mitochondrial $\mathrm{Bcl}-2$ does not contribute to inhibit apoptosis induced by $\mathrm{PrPSc}^{\mathrm{Sc}}$ (Figure 4D). Interestingly, the inhibition of cellular death in the clones expressing Bcl-2/ER was associated with a decrease in activation of caspase-12 (Figure 4E), further supporting the link between ER-stress and caspase-12 activation in the $\mathrm{PrP}^{\mathrm{Sc}}$ apoptotic pathway.

\section{PrPSc replication sensitizes N2A cells to ER-stress- induced apoptosis}

It has been described that a hypothalamic neuronal cell line persistently infected with scrapie prions has the ability to convert endogenous $\mathrm{PrP}^{\mathrm{C}}$ into $\mathrm{PrP}^{\mathrm{Sc}}$, and exhibits typical morphological and biochemical features of apoptosis (Schatzl et al., 1997). However, in most neuronal lines chronically infected with prions, including N2A cells, there are no signs of cellular death (Rubenstein et al., 1984; Butler et al., 1988). In order to analyze the effect of $\mathrm{PrP}^{\mathrm{Sc}}$ replication on cellular dysfunction, we studied the vulnerability to toxic stress of $\mathrm{N} 2 \mathrm{~A}$ cells chronically infected with $\mathrm{RML}$ prions $(\mathrm{ScN} 2 \mathrm{~A})$. These cells propagate protease-resistant prion protein (Figure 5A) and carry infectivity (Butler et al., 1988). Even though there are no evident effects on cellular viability following prion infection, treatment with different ER-stress inducers, including thapsigargin, tunicamycin, brefeldin $\mathrm{A}$ and the ionophore A23187, revealed that $\mathrm{ScN} 2 \mathrm{~A}$ cells are more sensitive to ER-stress mediated cell death than noninfected N2A cells (Figure 5B). In control experiments, no differential effect was observed when ScN2A and N2A cells were treated with inducers of mitochondrial stress, such as staurosporine (Figure 5C) or serum deprivation (data not shown). These data suggest that $\mathrm{PrP}^{\mathrm{Sc}}$ replication induces ER-stress, and although this does not lead directly to cell death, it nevertheless sensitizes the cells to subsequent apoptotic stimuli, which target the ERassociated pathway.

A possible explanation for the lack of toxicity of endogenous $\mathrm{PrP}^{\mathrm{Sc}}$ produced in $\mathrm{N} 2 \mathrm{~A}$ cells is that since these cells divide rapidly, they do not accumulate enough $\mathrm{PrP}^{\mathrm{Sc}}$ to lead to cell death. To test this hypothesis, we analyzed
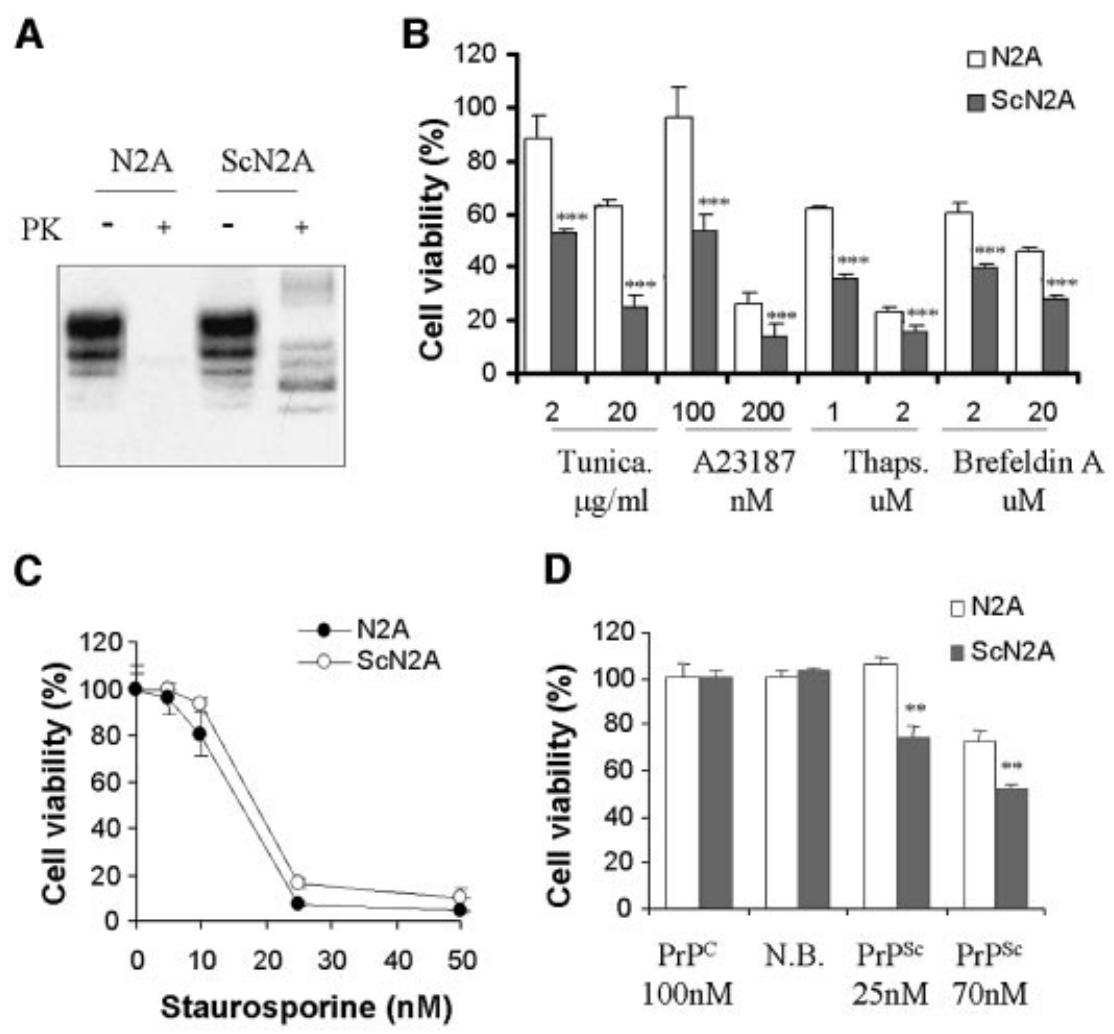

Fig. 5. PrPSc-replication sensitizes $\mathrm{N} 2 \mathrm{~A}$ cells to ER-stress mediated apoptosis. (A) Scrapie-infected N2A cells replicate the protease-resistant PrPSc form, whereas the non-infected cells contain only PK-sensitive PrPC, as analyzed by western blot. (B) ScN2A and N2A cells were treated with different concentrations of tunicamycin, A23187, thapsigargin (Thaps) or brefeldin A for $48 \mathrm{~h}$, and cell viability was quantified using MTS. Filled bars represent infected cells and empty bars indicates non-infected cells. Data were analyzed by $t$-test comparing the values of infected and non-infected cells for each treatment $(* * * P<0.005)$ and by two-way ANOVA using treatment and cells (infected and non-infected) as the variables $(P<0.0001)$. $(\mathbf{C})$ As controls, cells were treated with different concentrations of staurosporine for $48 \mathrm{~h}$, and cellular viability was quantified by MTS analysis. (D) N2A and $\mathrm{ScN} 2 \mathrm{~A}$ cells were treated with PrPSc, and cell viability was analyzed after $48 \mathrm{~h}$ using MTS. Data in panels (B, C and D) represent two independent experiments performed in triplicate. Parametric $t$-test was used to analyze statistical significance comparing for each condition the values of noninfected versus infected cells. 
the extent of cell death induced by purified $\mathrm{PrP}^{\mathrm{Sc}}$ in infected and non-infected N2A. Addition of $\mathrm{PrP}^{\mathrm{Sc}}$ to the culture medium produced a higher toxicity in $\mathrm{ScN} 2 \mathrm{~A}$ cells than in non-infected cells (Figure 5D). Interestingly, low concentrations of $\mathrm{PrP}^{\mathrm{Sc}}(25 \mathrm{nM})$ that in non-infected cells do not produce toxicity, in $\mathrm{ScN} 2 \mathrm{~A}$ lead to significant cell death (Figure 5D). No effects on cellular viability were observed when infected and non-infected cells were treated with recombinant $\mathrm{PrP}^{\mathrm{C}}$ or an equivalent sample prepared from non-infected brains (Figure 5D). These data reinforce the hypothesis that $\mathrm{PrP}^{\mathrm{Sc}}$ damages the cells by the ER-stress pathway.

\section{Neuronal loss in murine scrapie is associated with the activation of caspase-12 and the up-regulation of Grp58}

To validate the participation of caspase- 12 during the development of prion disease in vivo, C57BL/6J mice were infected with 139A-scrapie and caspase-12 activation was analyzed by western blotting in different brain areas of symptomatic animals. Figure 6A shows that the active fragments of caspase-12 (p42/35) can be detected mainly in the hippocampus, thalamus and brain stem, whereas no clear signal was detected in cortex and cerebellum. This pattern was representative of the results obtained in several animals in late stages of the disease. No evidence of active caspase- 12 fragments was ever detected in normal animals of the same age. The appearance of the active fragments was not paralleled by a noticeable decrease in pro-caspase- 12 signal, most likely because of the high complexity of the brain extracts in terms of cellular type diversity and the selective neuronal cell death observed in scrapie. In control experiments, we analyzed the activation of caspase-8, observing no significant changes in the pro-caspase- 8 form, and no increase in the levels of the active fragments (Figure 6A; p43/41). After histological analysis of the same brain areas it was possible to observe a correlation between the degree of caspase-12 activation and the extent of neuronal loss (Figure 6B). The highest levels of caspase-12 active fragments and neuronal death were found in the hippocampus, pyramidal cell layer and the thalamus, whereas in the cortex despite significant neuronal distortion little cell loss was observed, correlating with the absence of caspase12 activation.

We then analyzed markers of ER-stress in the brain of these animals. Our data showed a dramatic up-regulation of the ER-stress inducible chaperon protein Grp58 in all brain areas. No significant changes were detected in the expression levels of the chaperones Grp94, calnexin,

Fig. 6. Neuronal loss in murine scrapie is associated with activation of caspase-12 and up-regulation of Grp58. (A) Activation of caspase-12 and caspase- 8 was analyzed by western blotting in different brain areas, including anterior cortex (CxA), posterior cortex (Cxp), cerebellum (Cereb), brain stem (BS), thalamus (Thal) and hippocampus (Hip). (B) Neuronal loss in hippocampus, thalamus and cortex was measured by immunohistochemical staining with $\mathrm{Neu}-\mathrm{N}$, a neuronal-specific marker. (C) Expression levels of Grp58, Grp94 and Hsp70 were analyzed in the same brain areas described in (A). (D) $\mathrm{PrP}^{\mathrm{Sc}}$ levels were quantified after PK treatment of different brains areas from scrapie-infected and control animals. Results are representative of the data obtained with three different controls and scrapie-infected animals. The first lane shows a normal brain homogenate (NBH) before PK treatment.
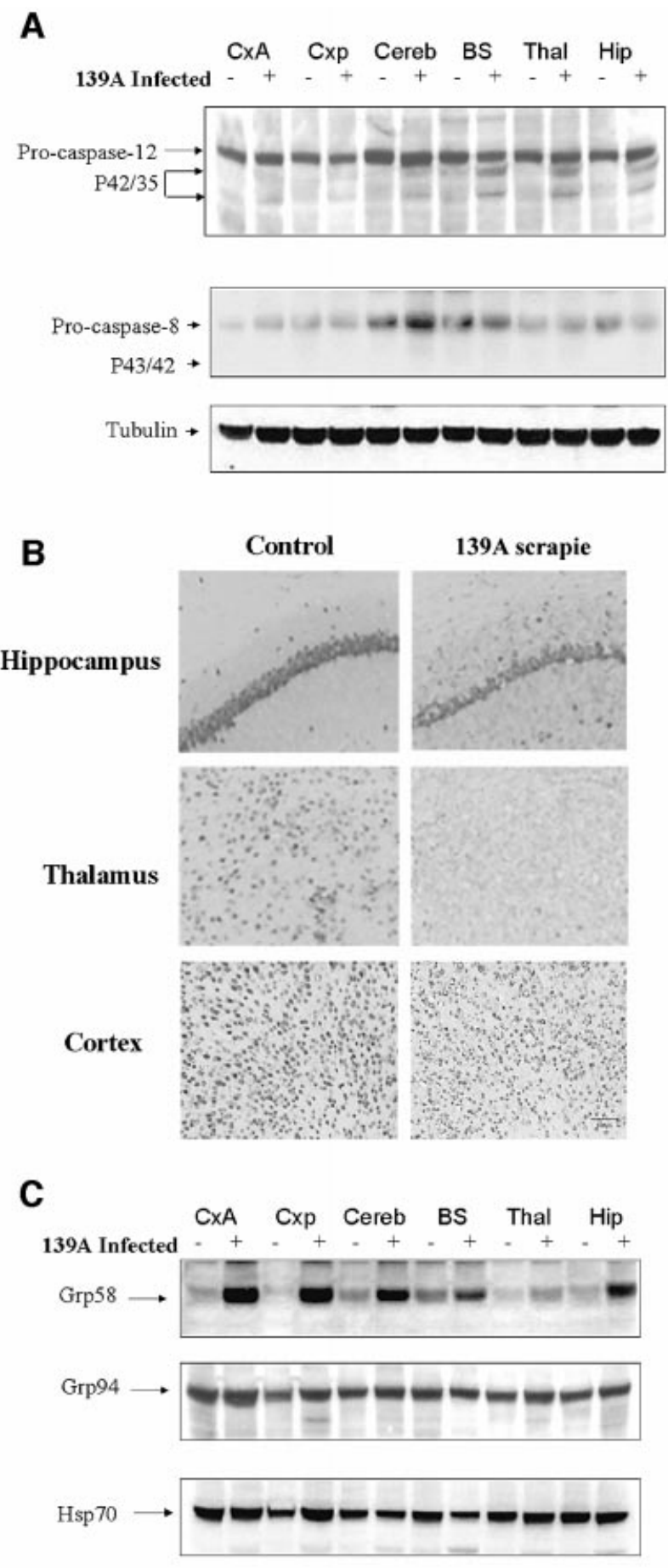

D

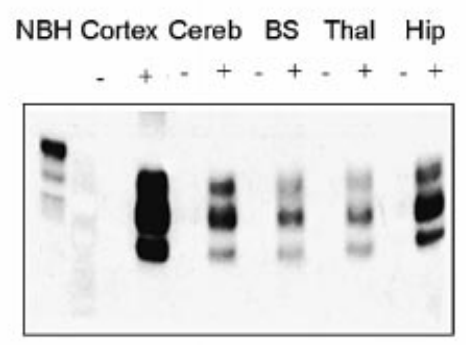


Hsp60 or Hsp70 (Figure 6C; and data not shown). The presence of $\mathrm{PrP}^{\mathrm{Sc}}$ was analyzed in the same brain areas by western blotting after PK treatment. As shown in Figure 6D, PrPSc accumulation directly correlates with the expression levels of Grp58, consistent with the idea that the accumulation of $\mathrm{PrP}^{\mathrm{Sc}}$ triggers a neuroprotective response involving up-regulation of some ER chaperones.

\section{ER-stress and caspase-12 activation in post mortem CJD brains}

The participation of ER-stress and caspase-12 activation was studied further in several human brain samples from patients affected with sCJD and vCJD. Western blot analysis of caspase- 12 activation revealed that the active fragments could be detected in all samples analyzed from patients (three sCJD and one vCJD), whereas these fragments were not clearly detected in six control samples from healthy individuals (Figure 7A). Interestingly, we were able to detect higher levels of the ER chaperones Grp58, Grp78, and Grp94 in sCJD and vCJD brains, compared with control samples (Figure 7A). No significant changes were observed in the Hsp70 protein levels. The levels of $\mathrm{PrP}^{\mathrm{Sc}}$ replication were analyzed after PK treatment (Figure 7B) and the results show that all samples analyzed contained abundant levels of PK-resistant PrP. In agreement with these data, the up-regulation of Grp58 in human samples of patients with SCJD has been recently reported (Yoo et al., 2002). However, the protein expression levels described by Yoo and co-workers were lower than the levels described here, possibly due to the fact that different brain areas (cerebellum instead of cortex) were examined in each case. Taken together, these data clearly implicate ER-stress and caspase-12 activation in neurodegeneration in humans affected by CJD.

\section{Discussion}

In this paper we describe for the first time the signalling pathways involved in neuronal apoptosis induced by brainderived $\mathrm{PrP}^{\mathrm{Sc}}$. Our results indicate that nanomolar concentrations of purified $\mathrm{PrP}^{\mathrm{Sc}}$ are sufficient to trigger apoptosis of neuroblastoma cells. This effect appears to be very specific for the pathological conformation of the protein, since no toxicity was observed using recombinant $\mathrm{PrP}^{\mathrm{C}}$, synthetic PrP peptides or $\mathrm{PrP}^{\mathrm{Sc}}$ treated with a peptide that disrupts $\beta$-sheet conformation. Apoptotic induction by $\mathrm{PrP}^{\mathrm{Sc}}$ was shown to be dependent on caspase-3 activation, evidenced by the detection of caspase- 3 activity after incubation with $\mathrm{PrP}^{\mathrm{Sc}}$, and the inhibition of toxicity by pretreatment of N2A cells with Ac-DEVD-fmk, a molecule that preferentially inhibits caspase-3. Since neither substrates nor inhibitors are totally specific, it is not possible to rule out the participation of other executor caspases, such as caspase-7. However, previous reports have also shown the involvement of caspase-3 in $\mathrm{PrPSc}_{\text {-induced cell }}$ death (Hetz and Soto, 2003). Our results also show that upstream of caspase- 3 activation there is a rapid and sustained release of calcium from the ER in response to $\mathrm{PrP}^{\mathrm{Sc}}$ treatment. Perturbation of calcium homeostasis and accumulation of misfolded proteins in the ER has been shown to elicit a cell-stress response that can lead to apoptosis (Nakagawa et al., 2000). Consistent with this hypothesis, we found that $\mathrm{PrP}^{\mathrm{Sc}}$ treatment leads to the
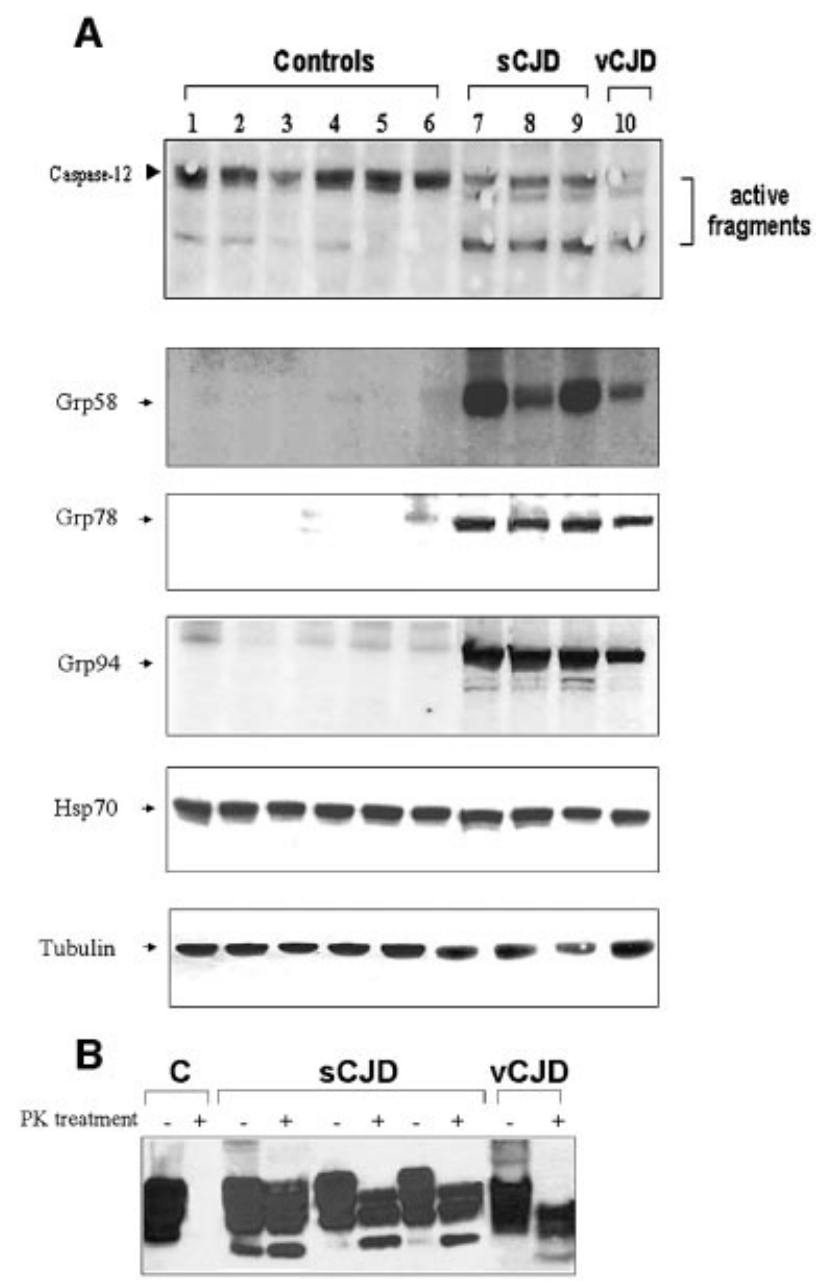

Fig. 7. Caspase-12 activation and induction of ER-stress markers in sCJD and vCJD human brain samples. (A) Analysis of caspase-12 activation and expression levels of Grp58, Grp78, Grp94 and Hsp70 were performed in human samples from cortex of six normal individuals (lanes 1-6), three individuals affected with sCJD (lanes 7-9) and one with vCJD (lane 10). As internal control of total protein levels, a western blot using anti-tubulin antibody is shown in the bottom panel. (B) $\mathrm{PrP}^{\mathrm{Sc}}$ levels were quantified after $\mathrm{PK}$ treatment from human samples of a normal individual or patients affected with CJD.

induction of ER chaperones of the glucose regulated family proteins (Grps). Experiments with $\mathrm{N} 2 \mathrm{~A}$ cells chronically infected with scrapie prions further support the relationship between PrPSc and ER-stress. Infected cells exhibit increased sensitivity to the ER-stress induced apoptosis mediated by several stimuli, including exogenous $\operatorname{PrP}^{\mathrm{Sc}}$ itself.

ER-stress has been associated with the pathogenesis of other neurodegenerative disorders, including Alzheimer disease, Parkinson's disease, Huntington disease and amyotrophic lateral sclerosis (Mattson, 2000; Sherman and Goldberg, 2001; Kouroku, 2002). These diseases are also characterized by accumulation of misfolded proteins in the brain (Soto, 2003). A molecular mechanism linking ER stress and apoptosis has been recently described, in which the ER-resident caspase-12 is activated, leading to caspase-3 activation and cellular death (Nakagawa et al., 2000). Treatment of neurons with $\beta$-amyloid peptide, or the expression of polyglutamine aggregates associated with Huntington disease induces ER stress and activation 
of caspase-12 in vitro (Nakagawa et al., 2000; Kouroku, 2002). It has been proposed that the main function of caspase-12 is to facilitate apoptosis in cells irreversibly damaged by stress signals from the ER (Mehmet, 2000). In our experiments, exposure of the cells to $\mathrm{PrP}^{\mathrm{Sc}}$ leads to a significant activation of caspase-12, reflected by the decrease in the signal of procaspase- 12 .

Our in vitro results are supported by biochemical and histological studies in scrapie mouse brains, which show a good correlation between neuronal death and caspase-12 activation. In addition, we found a direct correlation between the up-regulation of ER-stress inducible protein Grp58 and the levels of $\mathrm{PrP}^{\mathrm{Sc}}$ in different brain areas of scrapie-infected mice. Grp58, also called ER-60 or Erp-57, is a disulfide isomerase that forms part of the ER chaperone family designated as glucose regulated proteins (Grps) (Mazzarella et al., 1994). However, no good correlation was observed between $\mathrm{PrP}^{\mathrm{Sc}}$ deposition/Grp up-regulation and neuronal death/caspase-12 activation. The most likely explanation for these results is that $\mathrm{PrP}^{\mathrm{Sc}}$ replication and Grp58 expression are early events in the disease, whereas caspase-12 activation and neuronal loss occurs at late stages. Expression of Grp proteins may be down-regulated when the apoptotic programme is activated. An alternative explanation is that the extent of cellular loss might be associated with differential sensitivity to $\operatorname{PrP}^{\mathrm{Sc}}$ of neuronal cell types in each specific brain area. We are currently performing analyses at different time points after prion infection to address this issue. Preliminary results revealed that abundant $\mathrm{PrP}^{\mathrm{Sc}}$ accumulation and Grp58 up-regulation are observed in brain stem, thalamus and hippocampus early in the course of the disease and before extensive cell death or caspase-12 activation are observed (C.Hetz and C.Soto, unpublished data). As the disease progresses, caspase- 12 is activated and this is followed by neuronal death. However, it is possible that the brain regions affected and the degree of ER-stress response may be variable in different species/ strains. Indeed, in human brain from SCJD and vCJD a profound ER-stress response concomitant with caspase-12 activation was observed in cerebral cortex, a region with only mild effect in mice. Our findings, together with previous reports, suggest that caspase-12 may play a major role in neuronal apoptosis associated with protein misfolding and aggregation in the brain. The mechanism by which ER-stress and calcium release induces caspase12 activation in vivo remains to be investigated.

Based on our findings we can propose a pathway for $\mathrm{PrP}^{\mathrm{Sc}}$-induced apoptosis (Figure 8), in which the first step would be the interaction of $\mathrm{PrP}^{\mathrm{Sc}}$ with some as yet unknown cell surface receptor(s), which triggers a signal to the ER, resulting in release of intra-ER calcium (Figure 8). Our data do not rule out the possibility that $\mathrm{PrP}^{\mathrm{Sc}}$ migrates to the ER and by itself induces ER-stress and calcium release. ER-stress would then trigger the upregulation of certain chaperone proteins with neuroprotective activities (such as Grp58, Grp78 or Grp94) and activation of the ER-resident caspase-12, leading to the degradation of cellular proteins and cell death (Figure 8). ER chaperones are probably up regulated in an attempt to correct misfolded $\mathrm{PrP}^{\mathrm{Sc}}$ or to remove it via the delivery of the proteins towards the proteasomal degradation pathway. Grp proteins are a family of molecular chaperones located

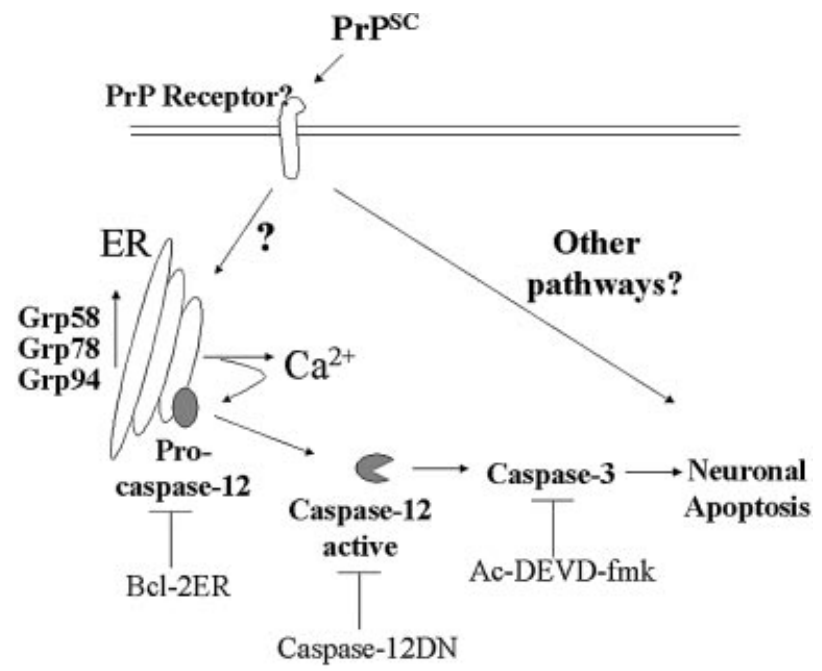

Fig. 8. A working hypothesis for $\mathrm{PrP}^{\mathrm{Sc}}$-induced apoptosis in neuronal cells. Interaction of $\mathrm{PrP}^{\mathrm{Sc}}$ with an unknown receptor protein activates a signaling pathway, which induces the release of calcium from the ER and ER-stress, as evidenced by the up-regulation of ER chaperones (i.e. Grp58, Grp78 and/or Grp94). ER-stress leads to activation of caspase 12 , which in turn cleaves and activates the executioner caspase- 3 , leading to apoptosis.

in the ER that have been shown to attenuate cellular death induced by increase of intracellular calcium and the accumulation of misfolded proteins in the ER (Mazzarella et al., 1994; Liu et al., 1997). However, no evidence is yet available on the interaction of PrP with Grps chaperones in vivo. Accumulation of PrP molecules in the ER has been shown to occur in cells expressing mutant forms of PrP linked to inherited forms of the disease (Singh et al., 1997; Zanusso et al., 1999; Jin et al., 2000; Negro et al., 2001). Interestingly, in neuroblastoma cells expressing mutant PrP, an association of the protein with Grp78 was detected, which appears to be important for proteasomal delivery and degradation of mutant PrP (Jin et al., 2000). In addition, stimulation of retrograde transport of PrP towards the ER favors the formation of $\mathrm{PrP}^{\mathrm{Sc}}$ in prioninfected N2A neuroblastoma cells (Beranger et al., 2002).

Our findings have clear implications for development of TSE treatments directed to prevent neurodegeneration. Since caspases are central to both normal programmed cell death and injury-dependent apoptosis, inhibition of these proteases usually results in serious adverse effects. However, caspase-12 appears not to be essential for normal development or physiological cell death, rather its activation seems confined to some specific pathological stress signals (Mehmet, 2000). Indeed, caspase-12deficient mice have no noticeable developmental or behavioural defects (Nakagawa et al., 2000). Therefore, inhibition of caspase-12 activation might provide a novel therapy for TSEs and other neurodegenerative diseases initiated by protein misfolding. However, until now the participation of caspase-12 in human pathologies has been controversial, since the functional human homologue has not been identified (Fischer et al., 2002). Despite this, a protein detectable with diverse anti-murine caspase-12 antibodies is present in several human cell lines (Bitko and Barik, 2001; Rao et al., 2001), and this putative human caspase-12 homologue exhibited similar involvement in 
ER-stress mediated apoptosis. Our data suggest that targeting caspase-12 or other components of the ER-stress mediated apoptotic pathway may lead to a novel therapy for TSEs.

\section{Materials and methods}

\section{Materials}

The fluorogenic caspase substrates (Ac-DEVD-amc, Ac-YVAD-amc), caspase inhibitors (Ac-DEVD-cho, Ac-YVAD-cho, zVAD-fmk), staurosporine, tunicamycin, brefeldin A, A23187, thapsigargin, ALLN, calpain inhibitor III and calpeptin were purchased from Calbiochem (Darmstadt, Germany). The cell-permeable caspase-3 substrate FAMDEVD-fmk was obtained from Promega (Madison, WI) and the cellpermeable caspase- 8 substrate FAM-LETD-fmk and caspase-1 substrate FAM-YVAD-fmk were purchased from Intergen (New York, NY). Cell culture medium, fetal calf serum, and antibiotics were obtained from Life Technologies (Maryland, USA). PrP106-126 and iPrP13 peptide were purchased from Neosystem Inc.

\section{PrPsc purification}

$\mathrm{PrP}^{\mathrm{Sc}}$ was purified from mice infected with 139A scrapie as previously described (Soto et al., 2000). Briefly, brain tissue was homogenized in PBS containing protease inhibitors and solubilized in $10 \%$ salkosyl. After centrifugation in a TL100 ultracentrifuge at 80000 r.p.m. for $2 \mathrm{~h}$ at $4^{\circ} \mathrm{C}$ over a sucrose gradient, pellets were resuspended in PBS containing $0.1 \%$ SB-314. Thereafter, samples were treated with PK $(30 \mu \mathrm{g} / \mathrm{ml})$ for $2 \mathrm{~h}$ followed by another sucrose gradient centrifugation at 80000 r.p.m. for $2 \mathrm{~h}$. The pellet was washed twice with PBS and resuspended in the same buffer. After this step, purity was $>95 \%$ as estimated by silver staining. $\mathrm{PK}$ treatment results in an N-terminally truncated version of $\mathrm{PrP}^{\mathrm{Sc}}$, lacking the first 90 residues, usually termed PrP27-30, which has been shown to keep the major properties of PrPsc including infectivity. PrPSc concentration was estimated by immunoblot analysis, using known concentrations of the recombinant mouse $\operatorname{PrP}^{\mathrm{C}}$ (Prionics Inc, Zurich, Switzerland).

\section{Cell culture, viability and apoptosis assays}

N2A cells were cultured in DMEM supplemented with $10 \%$ fetal calf serum and antibiotics $(10000 \mathrm{U} / \mathrm{ml}$ penicillin, $10 \mu \mathrm{g} / \mathrm{ml}$ streptomycin) at $37^{\circ} \mathrm{C}$ and $5 \% \mathrm{CO}_{2}$. For cell viability analysis, cells were grown in collagen IV-coated 96-well plates for $24 \mathrm{~h}$ in cell culture medium containing $1 \%$ serum before addition of the sample $\left(\mathrm{PrP}^{\mathrm{Sc}}\right.$ or other reagents). Cell viability was quantified using 3-(4,5-dimethylthazol-2-yl)5-3-carboxymethoxy-phenyl)-2-(4-sulfophenyl)-2H-tetrazolium (MTS) and phenazine methosulfate (PMS) according to the recommendations of the supplier (Promega, CellTiter96 ${ }^{\circledR}$ Aqueous, Madison, WI). In situ caspase-3/caspase-8/caspase-1 activity was detected using the fluorescent substrates following the manufacturer's instructions as previously described (Hetz et al., 2002b). Quantification of phosphatidylserine exposure in the outer leaflet of the plasma membrane was detected by flow cytometry using FITC-coupled annexin V (Roche, Basel, Switzerland) as previously described (Hetz et al., 2002b). For caspase inhibition experiments, cells were pre-incubated for $2 \mathrm{~h}$ with Ac-DEVDfmk $(100 \mu \mathrm{M})$, Ac-YVAD-fmk $(100 \mu \mathrm{M})$ or zVAD-fmk $(10 \mu \mathrm{M})$ before PrPSc addition. For PrP106-126 toxicity, $1 \mathrm{mM}$ peptide solution was incubated in PBS for $24 \mathrm{~h}$ at $37^{\circ} \mathrm{C}$ to induce aggregation, before addition to $\mathrm{N} 2 \mathrm{~A}$ cultures for cellular viability determinations at a final concentration of $100 \mu \mathrm{M}$ or $100 \mathrm{nM}$.

\section{Generation of N2A cells chronically infected with scrapie}

Stable chronically infected cells were established by subcloning the N2A neuroblastoma cells obtained from ATCC by limiting dilution, as described previously (Bosque and Prusiner, 2000). Individual subclones were tested for sensitivity to infection by the RML strain of mouse scrapie by adding $4 \mu \mathrm{l}$ of a $10 \%$ late stage infected brain extract. Cells were serially passed thereafter in the absence of $\mathrm{PrP}^{\mathrm{Sc}}$. After several passages individual cultures were tested for the presence of newly generated $\mathrm{PrP}^{\mathrm{Sc}}$ by western blotting.

\section{Measurement of intracellular calcium}

The changes in intracellular calcium levels resulting from $\operatorname{PrP}^{\mathrm{Sc}}$ treatment were measured in a FLIPR1 machine (Molecular devices, Sunnyvale, CA) using the fluorescent dye Fluo-4, which shows increased fluorescence at $515-535 \mathrm{~nm}$ after calcium binding. Cells were grown on black 96-wells plates coated with collagen IV and loaded for $2 \mathrm{~h}$ with Fluo-4 at a final concentration of $10 \mu \mathrm{g} / \mathrm{ml}$. The loaded cells were washed twice with FLIPR buffer $(150 \mathrm{mM} \mathrm{NaCl}, 5 \mathrm{mM} \mathrm{KCl}, 1 \mathrm{mM} \mathrm{MgCl} 2,10 \mathrm{mM}$ Hepes, $10 \mathrm{mM}$ glucose) and fluorescence emission was quantified for a total time of $30 \mathrm{~min}$. The basal fluorescence of the dye was usually determined before the addition of the samples and was assigned a value of zero. To determine the origin of intracellular calcium, cells were pretreated with thapsigargin $(5 \mu \mathrm{M})$ for $15 \mathrm{~min}$ before addition of the agonists.

\section{Cell transfection}

Expression vectors encoding Bcl-2 lacking the transmembrane domain (Bcl-2/ATM), wild-type Bcl-2 (Bcl-2/WT) and Bcl-2 mutants targeted to the outer membrane of the ER (Bcl-2/ER) were kindly provided by B.Leber (Ontario, Canada) and C.Belka (Tubingen, Germany). ERspecific targeting of Bcl-2 was achieved by exchanging the C-terminal insertional sequence of $\mathrm{Bcl}-2$ with equivalent sequence of the rat cytochrome b5. The distribution of ectopically expressed Bcl-2/ER, Bcl$2 / \mathrm{WT}$ and $\mathrm{Bcl}-2 / \Delta \mathrm{TM}$ in the selected clones was analyzed by coinmunolocalization with the ER marker calnexin and nuclei were stained with Hoechst33342. Expression plasmid containing catalytically inactive caspase-12 mutant lacking its N-terminal pro-domain (amino acids $1-94$, pC12DN) was kindly provided by R.Rao (California). Stably expressing N2a cells were produced by transfection using SuperFect (Qiagene, Valencia, CA) following the manufacturer's instructions. After $48 \mathrm{~h}$, cells were selected using hygromicin $(1.5 \mathrm{mg} / \mathrm{ml})$ for 5 days, and individual clones were obtained by limiting dilution.

\section{SDS-PAGE and western blot analysis}

Cells or brain tissue were homogenized on ice in RIPA buffer $(20 \mathrm{mM}$ Tris $\mathrm{pH} 8.0,150 \mathrm{mM} \mathrm{NaCl}, 0.1 \%$ SDS, $0.5 \%$ DOC, $0.5 \%$ Triton X-100) containing a protease inhibitor cocktail (Roche, Basel, Switzerland). Protein concentration was determined by micro-BCA assay (Pierce, Rockford, IL). The equivalent of $30-50 \mu \mathrm{g}$ of total protein was generally loaded onto 10\% SDS-PAGE minigels (Novex NuPage, Invitrogen Life Technologies, Basel, Switzerland) and analyzed by western blotting as described (Saborio et al., 2001). The following antibodies and dilutions were used: 6H4 anti-PrP, 1:10 000 (Prionics, Zurich, Switzerland), antiCaspase-12, 1:2000 (Exalpha, Watertown); anti-GRP78(Bip), antiHsp60, anti-Hsp70, anti-Grp58 and anti-Grp94 1:2000 (StressGene, San Diego, CA); anti-actin, 1:2000 (Santa Cruz); anti-tubulin, 1:5000 (Oncogene EMD Bioscience Inc., Darmstadt, Germany).

\section{Animal samples}

C57BL/6J mice were injected stereotaxically in the hippocampus with $1 \mu \mathrm{l}$ of a $10 \%$ brain homogenate from mice infected with 139A scrapie. The onset of clinical disease was measured weekly by determination of muscle strength using a grid system as described previously (Soto et al., 2000). Scrapie incubation times were defined from the date of injection to the time when the clinical symptoms persisted for three consecutives weeks, which for the conditions used in this study corresponded to 14 weeks after injection. For western blot analysis, sick animals were sacrificed 20 weeks after infection and different brain areas were dissected and analyzed separately.

\section{Human samples}

Frozen samples from brain cortex of clinically and pathologically confirmed cases of SCJD and VCJD were kindly provided by Dr Maurizio Pocchiari (Istituto Superiore di Sanita, Rome, Italy) and Dr James Ironside (CJD Unit, Edinburgh, UK), respectively. Brain samples from normal individuals were generously provided by Dr Adam Golabek (New York State Institute for Basic Research, Staten Island, NY).

\section{Immunohistochemistry}

Coronal $20 \mu \mathrm{m}$ sections were taken from the mouse dorsal hippocampus. Sections were fixed overnight in a solution containing $4 \%$ paraformaldehyde and transfered to a $20 \%$ sucrose solution. Immunostaining was performed on free-floating sections. Anti-Neu-N antibody was used to specifically stain neurons and detected with the avidin-biotin peroxidase method using reagents from Vector Laboratories (Vectastatin Elite ABC, Burlingame, CA) and diaminobenzidine as the chromogen.

\section{Statistical analysis}

Data were analyzed by parametric $t$-test (two-tailed) and significance was expressed as follow: $* P<0.05$; $* * P<0.01 ; * * * P<0.005$. When more than two groups were analyzed, an ANOVA test was also used to estimate statistical significance. 
Supplementary data

Supplementary data are available at The EMBO Journal Online.

\section{Acknowledgements}

We would like to thank James Ironside (CJD Unit, Edinburgh, UK), Maurizio Pocchiari, Franco Cardone (Istituto Superiore di Sanita, Rome, Italy) and Adam Golabek (New York State Institute for Basic Research, NY) for kindly providing postmortem samples of human brains from vCJD, sCJD and normal individuals. We also thank Drs B.Leber (Mc. Master University, Canada), C.Belka and J.Rudner (University of Tübingen, Germany) for giving us the Bcl-2 mutant constructs and Dr R.Rao (Buck Institute for Age Research) for kindly providing the caspase-12 dominant-negative mutant. We are very grateful to Sebastian Walchi for designing caspase-12 RNAi. We thank Bruno Antonsson (Serono) and Nibaldo Inestrosa (Catholic University of Chile) for critical reading of the manuscript and Elisabeth Vial, Serge Wolfersperger, Yves Humbert, Yves Cambet and Roberto Lia (Serono) for technical assistance.

\section{References}

Beranger,F., Mange,A., Goud,B. and Lehmann,S. (2002) Stimulation of PrPC retrograde transport toward the endoplasmic reticulum increases accumulation of PrPSc in prion-infected cells. J. Biol. Chem., 227, 38972-38977.

Bitko,V. and Barik,S. (2001) An endoplasmic reticulum-specific stressactivated caspase (caspase-12) is implicated in the apoptosis of A549 epithelial cells by respiratory syncytial virus. J. Cell. Biochem., 80, 441-454.

Bosque,P.J. and Prusiner,S.B. (2000) Cultured cell sublines highly susceptible to prion infection. J. Virol., 74, 4377-4386.

Budihardjo,I., Oliver,H., Lutter,M., Luo,X. and Wang,X. (1999) Biochemical pathways of caspase activation during apoptosis. Аnnu. Rev. Cell. Dev. Biol., 15, 269-290.

Butler,D.A., Scott,M.R.D., Bockman,M., Borchelt,D.R., Taraboulos,A., Hsiao,K.K., Kingsbury,D.T. and Prusiner,S.B. (1988) Scrapie-infected murine neuroblastoma cells produce protease-resistant prion proteins. J. Virol., 62, 1558-1564.

Fischer,H., Koenig,U., Eckhart,L. and Tschachler,E. (2002) Human caspase 12 has acquired deleterious mutations. Biochem. Biophys. Res. Commun., 293, 722-726.

Forloni,G., Angeretti,N., Chiesa,R., Monzani,E., Salmona,M., Bugiani,O. and Tagliavini,F. (1993) Neurotoxicity of a prion protein fragment. Nature, 362, 543-546.

Ghetti,B. et al. (1996) Prion protein amyloidosis. Brain Pathol., 6, 127145.

Hetz,C. and Soto,C. (2003) Protein misfolding and disease: The case of prion disorders. Cell Mol. Life Sci., 60, 133-143.

Hetz,C., Hunn,M., Rojas,P., Torres,V., Leyton,L. and Quest,A.F. (2002a) Caspase-dependent initiation of apoptosis and necrosis by the Fas receptor in lymphoid cells: onset of necrosis is associated with delayed ceramide increase. J. Cell Sci., 115, 4671-4683.

Hetz,C., Bono,M.R., Barros,L.F. and Lagos,R. (2002b) Microcin E492, a channel-forming bacteriocin from Klebsiella pneumoniae, induces apoptosis in some human cell lines. Proc. Natl Acad. Sci. USA, 99, 2696-2701.

Jin,T., Gu,Y., Zanusso,G., Sy,M., Kumar,A., Cohen,M., Gambetti,P. and Singh,N. (2000) The chaperone protein BiP binds to a mutant prion protein and mediates its degradation by the proteasome. J. Biol. Chem., 275, 38699-38704.

Kouroku,Y.F. (2002) Polyglutamine aggregates stimulate ER stress signals and caspase-12 activation. Hum. Mol. Genet., 11, 1505-1515.

Liu,H., Bowes,R.C.,III, van de Water,B., Sillence,C., Nagelkerke,J.F. and Stevens,J.L. (1997) Endoplasmic reticulum chaperones GRP78 and calreticulin prevent oxidative stress, $\mathrm{Ca}^{2+}$ disturbances, and cell death in renal epithelial cells. J. Biol. Chem., 272, 21751-21759.

Mattson,M.P. (2000) Apoptosis in neurodegenerative disorders. Nat. Rev. Mol. Cell Biol., 1, 120-129.

Mazzarella,R.A., Marcus,N., Haugejorden,S.M., Balcarek,J.M., Baldassare,J.J., Roy,B., Li,L.J., Lee,A.S. and Green,M. (1994) Erp61 is GRP58, a stress-inducible luminal endoplasmic reticulum protein, but is devoid of phosphatidylinositide-specific phospholipase C activity. Arch. Biochem. Biophys., 308, 454-460.
Mehmet,H. (2000) Caspases find a new place to hide. Nature, 403, 2930.

Nakagawa,T., Zhu,H., Morishima,N., Li,E., Xu,J., Yankner,B.A. and Yuan,J. (2000) Caspase-12 mediates endoplasmic-reticulum-specific apoptosis and cytotoxicity by amyloid-beta. Nature, 403, 98-103.

Negro,A., Ballarin,C., Bertoli,A., Massimino,M.L. and Sorgato,M.C. (2001) The metabolism and imaging in live cells of the bovine prion protein in its native form or carrying single amino acid substitutions. Mol. Cell. Neurosci., 17, 521-538.

O'Donovan,C.N., Tobin,D. and Cotter,T.G. (2001) Prion protein fragment $\operatorname{PrP}(106-126)$ induces apoptosis via mitochondrial disruption in human neuronal SH-SY5Y cells. J. Biol. Chem., 276, 43516-43523.

Post,K., Brown,D.R., Groschup,M., Kretzschmar,H.A. and Riesner,D. (2000) Neurotoxicity but not infectivity of prion proteins can be induced reversibly in vitro. Arch. Virol., 16, S265-S273.

Prusiner,S.B. (1998) Prions. Proc. Natl Acad. Sci. USA, 95, $13363-$ 13383.

Rao,R.V., Hermel,E., Castro-Obregon,S., del Rio,G., Ellerby,L.M., Ellerby,H.M. and Bredesen,D.E. (2001) Coupling endoplasmic reticulum stress to the cell death program. Mechanism of caspase activation. J. Biol. Chem., 276, 33869-33874.

Rao,R.V., Castro-Obregon,S., Frankowski,H., Schuler,M., Stoka,V., del Rio,G., Bredesen,D.E. and Ellerby,H.M. (2002) Coupling endoplasmic reticulum stress to the cell death program. An Apaf-1independent intrinsic pathway. J. Biol. Chem., 277, 21836-21842.

Reed,J.C. (2002) Apoptosis-based therapies. Nat. Rev. Drug Discovery, 1, 111-121.

Rubenstein,R., Carp,R.I. and Callahan,S.M. (1984) In vitro replication of scrapie agent in a neuronal model: Infection of PC12 cells. J. Gen. Virol., 65, 2191-2198.

Rudner,J., Lepple-Wienhues,A., Budach,W., Berschauer,J., Friedrich,B., Wesselborg,S., Schulze-Osthoff,K. and Belka,C. (2001) Wild-type, mitochondrial and ER-restricted Bcl-2 inhibit DNA damage-induced apoptosis but do not affect death receptor-induced apoptosis. J. Cell Sci., 114, 4161-4172.

Saborio,G.P., Permanne,B. and Soto,C. (2001) Sensitive detection of pathological prion protein by cyclic amplification of protein misfolding. Nature, 411, 810-813.

Schatzl,H.M., Laszlo,L., Holtzman,D.M., Tatzelt,J., DeArmond,S.J., Weiner,R.I., Mobley,W.C. and Prusiner,S.B. (1997) A hypothalamic neuronal cell line persistently infected with scrapie prions exhibits apoptosis. J. Virol., 71, 8821-8831.

Sherman,M.Y. and Goldberg,A.L. (2001) Cellular defenses against unfolded proteins: a cell biologist thinks about neurodegenerative diseases. Neuron, 29, 15-32.

Singh,N., Zanusso,G., Chen,S.G., Fujioka,H., Richardson,S. Gambetti,P. and Petersen,R.B. (1997) Prion protein aggregation reverted by low temperature in transfected cells carrying a prion protein gene mutation. J. Biol. Chem., 272, 28461-28470.

Soto,C. (2003) Unfolding the role of protein misfolding in neurodegenerative diseases. Nat. Rev. Neurosci., 4, 49-60.

Soto,C. et al. (2000) Reversion of prion protein conformational changes by synthetic $\beta$-sheet breaker peptides. Lancet, 355, 192-197.

Takahashi,A. (1999) Caspase: executioner and undertaker of apoptosis. Intl J. Hematol., 70, 226-232.

Vaux,D.L. and Korsmeyer,S.J. (1999) Cell death in development. Cell, 96, 245-254.

Wang,N.S., Unkila,M.T., Reineks,E.Z. and Distelhorst,C.W. (2001) Transient expression of wild-type or mitochondrially targeted Bcl-2 induces apoptosis, whereas transient expression of endoplasmic reticulum-targeted $\mathrm{Bcl}-2$ is protective against Bax-induced cell death. J. Biol. Chem., 276, 44117-44128.

Yoo,B.C., Krapfenbauer,K., Cairns,N., Belay,G., Bajo,M. and Lubec,G. (2002) Overexpressed protein disulfide isomerase in brains of patients with sporadic Creutzfeldt-Jakob disease. Neurosci. Lett., 334, 196200.

Zanusso,G., Petersen,R.B., Jin,T., Jing,Y., Kanoush,R., Ferrari,S., Gambetti,P. and Singh,N. (1999) Proteasomal degradation and $\mathrm{N}$-terminal protease resistance of the codon 145 mutant prion protein. J. Biol. Chem., 274, 23396-23404.

Received March 27, 2003; revised August 25, 2003; accepted August 27, 2003 